\title{
Piglets add some colour to transgenic story
}

\section{Nicola Nosengo}

Researchers in Italy and Australia are to introduce 18 transgenic piglets to a meeting in California next week, in an attempt to convince sceptics that their disputed transgenic methodology does indeed work. They say that the technique could be a cheap and efficient way to produce animals expressing multiple foreign genes.

Marialuisa Lavitrano of the University of Milan-Bicocca, together with a group led by Ian McKenzie at the Austin Research Institute in Melbourne, created the animals, which express up to three foreign test genes, using a method called sperm-mediated gene transfer (SMGT).

Lavitrano first reported the method in 1989, when she found that sperm cells can internalize foreign DNA fragments, integrate the fragments' genes into their chromosomes, and then transfer these genes to the next generation during fertilization. But many laboratories were unable to repeat her results, probably because key factors such as optimal incubation temperature and the time required for DNA integration — vary widely, even between animals of the same species.

Lavitrano hopes to win over the doubters when she discusses the piglets on 11 August

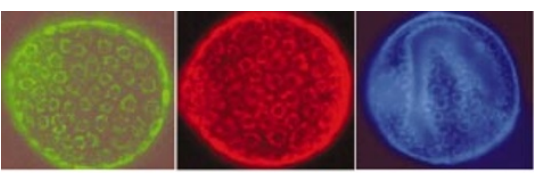

Colour code: a pig embryo, seen through colour filters, reveals expression of three foreign genes.

at the Transgenic Animal Research Conference in Lake Tahoe, California. Together with her Australian colleagues, she transferred test genes encoding coloured proteins — green, red and blue — into sperm cells and used them to inseminate female pigs.

The technique was surprisingly successful: of more than 100 embryos created, $90 \%$ expressed all three genes. And when two of the sows gave birth in Bologna, Italy, on 20 April, seven piglets contained all three coloured proteins, another seven contained two, and the remaining four displayed one.

The results are "big news", says Bob Wall, a researcher with the US Department of Agriculture in Beltsville, Maryland. SMGT - in the hands of Lavitrano and McKenzie, at least - has a better success rate than other, more widely used transgenic techniques, such as DNA micro-injection and nuclear transfer.
DNA micro-injection, which involves injecting DNA fragments into a fertilized egg, results in fewer than $1 \%$ of injected eggs giving rise to healthy animals expressing transgenes. And nuclear transfer, in which the nucleus of a genetically engineered adult cell is transferred to an egg cell whose nucleus has been removed, has an efficiency of 1-2\% in livestock, and has not yet led to successful multiple gene transfer.

Animals expressing multiple foreign genes will be important in studying the feasibility of organ transplantation from pigs to people, says Lavitrano. Introducing a suite of genes to make pig organs more similar to those of humans could help to prevent their rejection by the recipient's immune system, she says.

But companies still doubt that SMGT will be commercially viable. Tom Newberry of Genzyme Transgenics Corporation in Framingham, Massachusetts, says that micro-injection and nuclear transfer are inefficient but more commercially attractive, as they do not require specific lab conditions for each animal.

"SMGT could be important for smaller laboratories that cannot afford to handle the large numbers of animals that inefficient methods require," he adds.

\section{WHO prepares for final push to rid the world of polio}

\section{Declan Butler}

With the fight against polio close to being won, the newly appointed director-general of the World Health Organization (WHO), Lee Jong-wook, announced on 29 July that eradication of the disease by 2005 is one of his top priorities. But he said that more funds are needed to do the job properly.

Health workers agree that a final big push is needed. Poliovirus samples remain unmonitored in non-secure freezers across the world, and some vaccination programmes are lax. Any complacency threatens to undo years of gains, they say.

The WHO's US\$3-billion Global Polio Eradication Initiative, launched in 1988, has been highly successful, slashing the number of polio cases from 350,000 in 125 countries to just 235 in seven countries this year.

"But there is a false sense of security that the end is in sight," says David Heymann, the official appointed by Lee to lead the new push. The virus must be eliminated in the few countries where it remains, warns Heymann, as even a single case could spawn an outbreak that could be exported.

Lee has launched a three-month mass vaccination campaign, involving 175 million

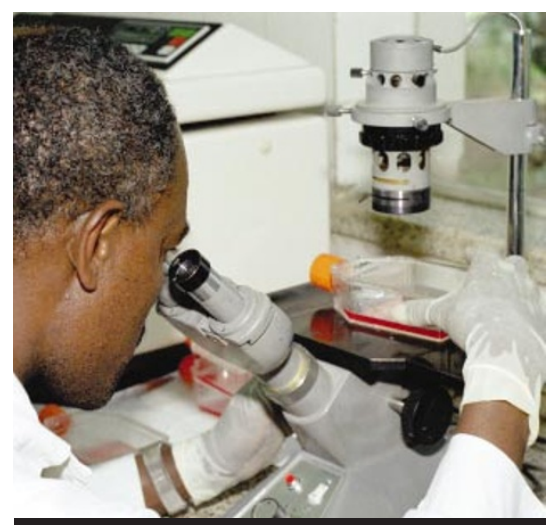

Closing in: a worker at Ethiopia's National Polio Laboratory in Addis Ababa.

children in India, Nigeria, Pakistan and Egypt, to eliminate polio transmission by the end of 2004. But before polio can be declared the second disease to be eradicated (after smallpox in the 1970s), sources of potential new outbreaks must be contained.

A major source might be the widely used oral polio vaccine, an attenuated live virus that can mutate back to wild, virulent poliovirus in unvaccinated populations and cause outbreaks (see Nature 409, 278-280; 2001).

"If this happens often we could be in trouble," admits Heymann. An alternative is the injectable Salk inactivated polio vaccine, which cannot cause disease. But this is hard to use efficiently in developing countries.

Poliovirus stocks held in laboratories across the world present another potential source of outbreaks. To stop this, the WHO this month launched a "Global action plan for laboratory containment of wild polioviruses", akin to the 1970s programme that targeted smallpox stocks. This requires countries to search for stocks and either destroy them or, if they are needed to provide live virus for vaccine manufacture, store them in biosecure facilities.

There are also other potential sources of infection. Diagnostic stool samples from polio patients contain live poliovirus and are widely stored, "possibly in their thousands", says Heymann. The WHO has responded by launching a stool inventory. Poliovirus contamination of laboratory cultures of other viruses has also been reported (M. Davies et al. Lancet 361, 1187-1188; 2003). 